\title{
El derecho a no presentar documentos inexigibles o reiterativos
}

\author{
Teresa Dolores Núñez Gómez \\ Becaria de Investigación
}

Sumario: I. INTRODUCCIÓN. II. LAS OBJECIONES DOCTRINALES A LA CONSTRUCCIÓN DEL DERECHO A NO PRESENTAR DOCUMENTOS INEXIGIBLES O REITERATIVOS COMO DERECHO PÚBLICO SUBJETIVO. III. EL DERECHO A NO PRESENTAR DOCUMENTOS INEXIGIBLES O REITERATIVOS COMO DERECHO DE LIBERTAD. 1. Los sujetos del derecho. a) El ciudadano. b) La Administración. IV. EL CONTENIDO DEL DERECHO: LA FACULTAD DE NO PRESENTACIÓN. V. RECAPITULACIÓN.

\section{INTRODUCCIÓN}

A pesar de constituir una de las novedades de la LRJAP, la relación de «derechos procedimentales» ${ }^{1}$, regulada en su artículo 35 , ha recibido una escéptica acogida por parte de la doctrina, fundada en buena medida en la consideración de que una parte de dichos derechos no son verdaderos derechos subjetivos.

Dentro de este grupo se encuentra el derecho que nos ocupa, enunciado en el apartado f), que denominaremos derecho a no presentar documentos inexigibles o reiterativos, que ha sido uno de los más discutidos, puesto que su existencia había sido ya cuestionada en sede parlamentaria donde fue presentada una enmienda de supresión del mismo por considerar que, en realidad, se trataba de una obligación de la Administración ${ }^{2}$.

Dicho derecho ha atraído nuestra atención por dos motivos fundamentales. En primer lugar, se dirige a atajar uno de los comportamientos burocráticos endémicos de la Administración que más dificulta sus relaciones con los administrados: las peticiones abusivas de documentación. En segundo lugar, porque, a pesar de su aparente modestia, un correcto empleo del mismo podría coadyuvar tanto a la consecución del objetivo de

\footnotetext{
1 L. Tolivar Alas: «Sobre el carácter novedoso de algunos derechos procedimentales», Revista Española de Derecho Administrativo (REDA), núm. 80, octubre-diciembre, 1993, pp. 623 y ss.

2 Enmienda núm. 447, presentada por el Partido Popular (DOCG Congreso de los Diputados, de 7 de mayo de 1992, serie A. núm. 82-6).
} 
REAL-2002, núm. 290. NÚÑEZ GÓMEZ, TERESA DOLORES. EL DERECHO A NO PRESENTAR DOCU...

REAL 290 (SEPTIEMBRE-DICIEMBRE, 2002)

simplificación procedimental que persigue la LRJAP como al aumento de la eficacia y coordinación de las Administraciones públicas.

Por tanto, intentaremos a lo largo de este estudio analizar las objeciones doctrinales fundamentales respecto a su naturaleza jurídica para, posteriormente, abordar la construcción del mismo como derecho público subjetivo de los administrados y analizar sus elementos fundamentales.

\section{LAS OBJECIONES DOCTRINALES A LA CONSTRUCCIÓN DEL DERECHO A NO PRESENTAR DOCUMENTOS INEXIGIBLES O REITERATIVOS COMO DERECHO PÚBLICO SUBJETIVO}

Si bien no faltan autores que no consideran que exista problema alguno en el reconocimiento del mismo como derecho público subjetivo ${ }^{3}$, a los que se une la postura unánime de la jurisprudencia a la que no se ha extendido dicho debate y que lo aplica sin cuestionar en ningún caso su naturaleza jurídica ${ }^{4}$, la doctrina mayoritaria le niega tal condición, entendiendo que nos hallamos en presencia de una prohibición dirigida a la Administración que actuaría como eliminadora de la antijuridicidad en un expediente sancionador dirigido contra el administrado por no haber presentado el documento requerido o que excluiría una eventual causa de caducidad de los procedimientos o derechos sustantivos discutidos en los mismos ${ }^{5}$. Del análisis de estas opiniones podemos deducir que la objeción de fondo que ambas efectúan se centra en la inadecuación de la técnica del derecho subjetivo respecto del contenido del derecho, conclusión que se deriva, a nuestro juicio, tanto del contenido negativo del mismo como de una errónea apreciación de la capacidad de elección del legislador.

Por lo que respecta a la primera objeción, es necesario recordar que nada impide la existencia de derechos públicos subjetivos de contenido

\footnotetext{
3 A. Embid Irujo: El ciudadano y la Administración, INAP, Madrid, 1994, pp. 57 y ss.

${ }^{4}$ Por todos, STSJ (Canarias-Sta. Cruz de Tenerife) de 4 de marzo de 1997 (Ar. 608), que incluso lo aplica retroactivamente a efectos interpretativos. Aunque el Tribunal Supremo no ha tenido ocasión de pronunciarse sobre este derecho concreto si lo ha hecho sobre otro similar y estrechamente relacionado con el derecho que nos ocupa — por todas, STS de 12 de septiembre de 1997 (Ar. 6929), sobre el derecho a obtener información de los requisitos de las solicitudes (artículo 35. g) sin cuestionar la naturaleza jurídica del mismo.

${ }^{5}$ Por todos, R. Parada Vázquez: El Régimen Jurídico de las Administraciones Públicas y del Procedimiento Administrativo Común, Marcial Pons, Madrid, 1999, pp. 157 y ss.
} 
negativo, especialmente si tenemos en cuenta que el derecho de propiedad, derecho subjetivo por excelencia, pertenece a dicha categoría ${ }^{6}$.

Por lo que respecta a la capacidad de opción legislativa, es necesario recordar que comprende no sólo la carga ideológica que tiñe los fines que persigue la norma, lícitos siempre y cuando éstos respeten los límites materiales que la Constitución impone, sino también la elección de las técnicas jurídicas más apropiadas para la consecución de los mismos. En el caso que nos ocupa, los fines perseguidos - la mayor importancia del administrado en la relación jurídico-administrativa, la modernización de la Administración y el incremento de la eficacia de la misma- son evidentes y ajustados a los principios constitucionales ${ }^{7}$. En cuanto a la elección de la técnica jurídica, se consideró el derecho subjetivo como el mecanismo más apropiado para atajar el problema de las peticiones abusivas de documentación, tanto por el papel activo que otorga al administrado, como por su efectividad, ya que constituye la forma más clara de legitimación frente a los tribunales, elección que, como veremos detalladamente, no atenta contra la naturaleza jurídica de la institución.

Mención aparte merecen aquellos que entienden que, aunque no se encontraba reconocido como tal en la legislación anterior, asistía al administrado en sus relaciones con la Administración ${ }^{8}$. Es evidente que el Ordenamiento siempre ofrece algún medio de defensa frente a una conducta abusiva, pero no todos son igualmente eficaces. Mientras un derecho subjetivo apodera al administrado con el máximo nivel de legitimación activa para iniciar la vía contencioso-administrativa, anteriormente debía demostrarse la existencia de un interés legítimo que había sido vulnerado por la conducta ilícita de la Administración ${ }^{9}$. Este escenario nos sitúa ante un caso de desviación de poder que es el mecanismo jurídico-administrativo para reaccionar contra los actos ilícitos atípicos ${ }^{10}$. Teniendo en cuen-

\footnotetext{
6 S. Romano: «Il diritto pubblico subbiettivo», en la obra colectiva Primo trattato completo di Diritto amministrativo italiano, Società Editrice Libraria, Milán, 1900, p. 16, según el cual la facultad principal derivada del mismo y presupuesto necesario del ejercicio del resto de facultades que conlleva, consiste en no ser perturbado en la pacífica posesión de la cosa.

7 Aps. 9, 3 y 4 de la Exposición de Motivos de la LRJAP.

8 J. GonzÁlez Pérez: Comentarios a la Ley de Régimen Jurídico de las Administraciones Públicas y el Procedimiento Administrativo Común (Ley 30/1992, de 26 de noviembre), Civitas, Madrid, 1999, p. 930.

9 Se trataría del interés a que la Administración ejerza, en el caso concreto, sus potestades de acuerdo con la legalidad en orden a la satisfacción de los derechos o intereses que se sustancian en el procedimiento.
}

10 M. Atienza y J. Ruiz Manero: Ilícitos atípicos. Sobre el abuso del derecho, el fraude de ley y 
ta las dificultades probatorias que afectan a la desviación de poder, podemos concluir que el administrado no se encontraba excesivamente amparado frente al problema de las exigencias abusivas de documentación ${ }^{11}$.

\section{EL DERECHO A NO PRESENTAR DOCUMENTOS INEXIGIBLES O REITERATIVOS COMO DERECHO DE LIBERTAD}

Tanto la doctrina favorable a la consideración del derecho cuyo estudio nos ocupa como la jurisprudencia, a pesar de afirmar su naturaleza de derecho subjetivo, no se han ocupado ni de analizar con detalle el porqué de dicha calificación ni de determinar el encuadramiento del mismo dentro de alguna de las distintas categorías de derechos subjetivos públicos existentes. Por ello, intentaremos en primer lugar encuadrar el derecho a no presentar documentos inexigibles o reiterativos en el concepto de derecho público subjetivo para después tratar de determinar su pertenencia a algún tipo concreto.

No es este estudio el lugar oportuno para relatar la historia del desarrollo del derecho subjetivo público como institución. Basta con hacer constar que, una vez superado el debate en torno a la existencia o no de los mismos, no hay problema en admitir que el ciudadano es titular de derechos subjetivos frente al Estado como consecuencia de que las relaciones entre ambos se conciban como relaciones jurídicas ${ }^{12}$. Es en el marco de estas relaciones en las que surgen los derechos subjetivos ${ }^{13}$ y no cabe duda de que la relación que une a la Administración y el administrado mediante un procedimiento administrativo es una relación jurídica, en cuanto detalladamente regulada por el Derecho, la cual es apta para generar derechos subjetivos. Sin embargo, dicha relación presenta una peculiaridad que forzosamente ha de afectar a cualquier derecho surgido de la misma: su instrumentalidad. La relación procedimental no es un fin en sí misma considerada, sino el medio a través del cual se pretende la satisfacción de otros derechos o intereses que subyacen a la misma, lo que le confiere un cier-

la desviación de poder, Trotta, Madrid, 2000. Dichos ilícitos son aquellos que se oponen a los principios del Ordenamiento afectando, por tanto, al elemento funcional de la norma jurídica, vid. idem, pp. 9 y ss.

\footnotetext{
11 Aproximadamente el $60 \%$ de las sentencias desestimatorias en esta materia lo son por falta de pruebas según C. Chinchilla Marin: La desviación de poder, Civitas, Madrid, 1989, p. 132.

12 S. Romano: «Il diritto pubblico subbiettivo», op. cit., p. 117.

13 G. JellineK: Sistema dei diritti pubblici subbiettivi, Società Editrice Libraria, Milán, 1911, p. 46.
} 
to grado de indeterminación en su contenido. Sin embargo, a nuestro juicio, ello no le priva de su condición sustancial de relación jurídica ni, como veremos, de la posibilidad de generar derechos subjetivos.

Desde que JELLINEK aunara las teorías de la voluntad y del interés en la construcción de su concepto de derecho público subjetivo, éste viene definiéndose como «la potestad de querer que tiene el hombre, reconocida y garantizada por el ordenamiento jurídico, en cuanto se refiere a un bien o interés» ${ }^{14}$. De esta definición se deduce que el derecho subjetivo consta de dos elementos, formal y material. La potestad o voluntad de querer constituiría el elemento formal y el bien o interés el elemento material y ambos deben estar en relación ya que la voluntad no es algo abstracto sino dirigido a la satisfacción del bien o interés, que es lo que el derecho reconoce y garantiza ${ }^{15}$. Por tanto, es necesario verificar que el derecho que nos ocupa cumple con las exigencias derivadas de ambos elementos para poder declarar que nos hallamos ante un auténtico derecho subjetivo público.

El elemento material ha de estar constituido por un interés individual ${ }^{16}$, que puede ser tanto de naturaleza económica como derivado de la condición de ciudadano y para cuyo reconocimiento es necesario que el interés individual se corresponda con un interés del Estado ${ }^{17}$. De estas reflexiones se derivan dos consecuencias. Por una parte, lo esencial del interés constitutivo del derecho subjetivo es que no está materialmente limitado, ya que puede derivarse de la condición del individuo respecto al Estado. Estas condiciones no se limitan a la de ciudadano sino que existen más formas de personalidad frente al poder público, una de las cuales es la de administrado ${ }^{18}$. Por otra, lo fundamental en orden al reconocimiento del interés no es su contenido sino la correspondencia del mismo con un análogo interés estatal.

Como hemos visto en el apartado anterior, el interés propio de este derecho consiste en la satisfacción de los derechos o intereses que se sustancian en el procedimiento administrativo. Es, por tanto, un interés de

\footnotetext{
14 Cfr. ibidem, p. 49.

15 Ibidem, pp. 49 y ss.

${ }^{16}$ Ibidem, p. 58.

17 S. Romano: «Il diritto pubblico subbiettivo», op. cit., pp. 123 y ss.

18 G. Jellinek: Sistema dei diritti pubblici subbiettivi, op. cit., p. 94, considera que la personalidad consiste en una relación con el Estado que cualifica al individuo, atribuyéndole una condición o status. A nuestro juicio, resulta aplicable la idea de que la condición de administrado supone un status en tanto comporta una calificación de la personalidad determinada por la relación con una manifestación del poder estatal.
} 
naturaleza instrumental consecuencia de la instrumentalidad consustancial a la relación en la que se genera, cuya función es coadyuvar a la satisfacción de otros derechos o intereses. Sin embargo, esto no afecta a las características propias del interés básico de un derecho subjetivo ya que no sólo se deriva de la condición de administrado, que es una de las formas de personalidad individual frente al Estado, sino que además coincide con un interés del Estado, la defensa del sistema. Dicho interés, en sentido amplio, incluiría la proscripción de aquellas conductas que atenten contra los principios inspiradores del mismo cuya observancia es deber del Estado garantizar. Es evidente que las solicitudes abusivas de documentación suponen un comportamiento que atenta contra las bases del procedimiento administrativo, ya que no sólo es contrario a la dimensión garantista del mismo, fundada en el principio de legalidad dado que carecen de respaldo normativo alguno y vulneran la finalidad de sus normas, inspiradas en el principio pro actione, sino que además suponen un comportamiento que atenta contra el principio de eficacia que está en la base de la dimensión de garantía del interés público del procedimiento administrativo. La conjunción de dichos elementos nos lleva a estimar que es interés suficiente para sustentar un derecho subjetivo.

Por lo que se refiere al elemento formal, la característica distintiva del derecho subjetivo consiste en el reconocimiento y garantía de la voluntad individual ya que la existencia de protección jurídica de un interés no siempre se verifica mediante esta técnica ${ }^{19}$. El necesario reconocimiento de una voluntad individual sitúa al derecho dentro del género de los poderes, entendidos como manifestaciones de capacidad ${ }^{20}$. La atribución de capacidad consiste, en el caso que nos ocupa, en la posibilidad de remoción del acto injusto entendido como el contrario al contenido de derecho. Este reconocimiento de capacidad ha de verificarse a través de algún medio jurídico, es decir, a través de una norma o acto jurídico, reconocimiento que ha sido realizado mediante ley.

Por tanto, puede decirse que el derecho a no presentar documentos inexigibles o reiterativos cumple con los requisitos formal y material de un derecho subjetivo. La doctrina añade a ambos requisitos la voluntad del legislador. Estaríamos, según esto, en presencia de un derecho subjetivo cuando la voluntad del legislador ha sido tutelar el interés individual y, a la vez, reconocer la voluntad individual. En el caso del derecho que nos

\footnotetext{
19 Ibidem, p. 122.

20 S. Romano: Fragmentos de un diccionario jurídico, Ediciones Jurídicas Europa-América, Buenos Aires, 1964, p. 299.
} 
ocupa la presencia de ambos es evidente, ya que la propia Exposición de Motivos de la LRJAP establece que estos derechos se añaden a los ya existentes para asistir a los ciudadanos en el procedimiento administrativo, lo que demuestra la voluntad de ampliar la esfera jurídica de los mismos. Dado el interés constitutivo del derecho ya se encontraba encuadrado dentro de la categoría de los intereses legítimos la única ampliación posible sería su consideración como derecho subjetivo.

Es además un derecho público subjetivo según todos los criterios que se han elaborado para la distinción de los mismos respecto de los derechos subjetivos privados. Sería público tanto si le aplicamos el criterio de la norma de la que se deriva ya que ésta es, inequívocamente, una norma de Derecho público como si recurrimos a la doctrina del carácter obligatorio de tales derechos, puesto que es inalienable por derivar de una condición personal ${ }^{21}$. Igualmente lo sería si consideramos el hecho de que es el ordenamiento el que ha concedido una capacidad que no se deriva de la libertad natural ${ }^{22}$. Por último, también sería público si consideramos que se produce en una relación entre el administrado y la Administración en la que ésta aparece en su calidad de poder público ${ }^{23}$.

Una vez establecida su naturaleza jurídica pasaremos a determinar cuál es su encaje sistemático en la categoría del derecho subjetivo público. Parte de la doctrina considera a algunos de los derechos contenidos en el artículo 35, aunque no el que examinamos, en la categoría de los derechos reaccionales por lo que intentaremos, en primer lugar, analizar si el derecho reaccional es el tipo de derecho subjetivo apropiado para configurar el que nos ocupa.

Los llamados derechos reaccionales se hayan estrechamente vinculados con la idea de libertad, entendida no en un sentido filosófico o político sino jurídico, es decir, el no estar más que sometido a la ley y poder hacer todo lo que la misma no prohíba ${ }^{24}$.

Esta libertad jurídica conforma el llamado «círculo vital» que no puede ser desconocido por la Administración ${ }^{25}$. Ello genera un derecho abstrac-

\footnotetext{
21 Ibidem, pp. 124 y ss.

22 G. JellineK: Sistema dei diritti pubblici subbiettivi, op. cit., pp. 55 y ss.

23 S. Romano: «Il diritto pubblico subbiettivo», op. cit., pp. 128 y ss.

24 G. Jellinek: Sistema dei diritti pubblici subbiettivi, op. cit., p. 115 y S. Romano: «Il diritto pubblico subbiettivo», op. cit., p. 163.

25 E. García de EnTERría: «Sobre los derechos públicos subjetivos», REDA, núm. 75, julio-septiembre, 1992, p. 441 y STS de 4 de febrero de 1991 (Ar. 1241)
} 
to de libertad entendida como integridad del propio círculo vital. Cuando la Administración dicta un acto ilegal, la conjunción del perjuicio que ello causa con la ilegalidad de la actuación hace nacer un derecho subjetivo concreto, el derecho a eliminar el perjuicio que es un derecho de defensa o protección. Por tanto, la ley objetiva, el deber de observar la legalidad, se descompone en un conjunto de situaciones subjetivas ${ }^{26}$.

Como puede observarse, este tipo de derecho pretende desterrar la distinción entre interés legitimo y derecho subjetivo reduciendo la cuestión a diferentes categorías de derechos: derechos de naturaleza patrimonial, derechos creados, reconocidos o declarados por actos administrativos singulares a favor de una persona determinada, situaciones de libertad individual articuladas como derechos ${ }^{27} \mathrm{y}$, finalmente, los derechos reaccionales, que vendrían a englobar lo que la jurisprudencia considera intereses legítimos. Ello supone un notable e ingenioso intento de acercar el régimen de legitimación de los intereses legítimos al de los derechos subjetivos en orden a obviar el inconveniente principal del interés: la carga de la prueba de su existencia. El derecho reaccional otorga, por tanto, la legitimación automática propia de los derechos subjetivos centrando la carga de la prueba en la existencia de perjuicio.

Sin embargo, pese al enorme potencial que dicha doctrina encierra, no estimamos que sea aplicable al caso que nos ocupa ya que el propio concepto de derecho reaccional lleva implícita la nota de la indeterminación. Es el derecho a eliminar el perjuicio, a restablecer el círculo vital y nace una vez violado el deber de observar la legalidad impuesto a la Administración, cuyo contenido se individualiza en el momento en que se comete un acto ilegal por parte de la misma. Este dato sería suficiente para descartar la configuración del derecho que nos ocupa como derecho reaccional ya que su reconocimiento legal le dota de existencia previa, singulariza su contenido y los sujetos del mismo. No nace en el momento del perjuicio, sino que preexiste al mismo y configura una obligación subjetiva de la Administración frente a todo administrado que se encuentre en la relación jurídica configurada por el procedimiento administrativo.

Es, a nuestro juicio, un derecho de libertad, el cual tiene un fundamento similar al reaccional en cuanto derivado de la libertad en sentido jurídico, ya que ésta es el bien jurídico protegido por el mismo. La doctrina del derecho subjetivo público establece que todo lo que subjetivamente apare-

\footnotetext{
26 Ibidem, pp. 442 y ss.

27 Ibidem, p. 428.
} 
ce como interés objetivamente considerado es un bien ${ }^{28}$. Hemos visto cómo el interés protegido en este caso es la satisfacción de los derechos o intereses que se sustancian en el procedimiento administrativo, los cuales objetivamente considerados pertenecen al ámbito de la libertad del sujeto, al círculo vital en el que la Administración no puede intervenir ilegalmente. Su definición como la facultad concedida al ciudadano de remover los impedimentos que el Estado impone a una actividad que la ley no le impide, permite la creación de nuevos derechos de libertad que protejan distintos contenidos de este bien jurídico, en función de cuáles sean los impedimentos que el poder público oponga a dichas actividades, tal y como ocurre en el presente caso con el fenómeno de la documentación abusiva $^{29}$.

Además, las características de este tipo de derechos corren parejas con las del derecho que nos ocupa. En primer lugar, tienen un contenido negativo. En segundo lugar, no supone el ejercicio material de una actividad ${ }^{30}$. Por último y, a nuestro juicio, la más importante, se ejercita mediante la resistencia individual a la orden de la autoridad que intenta violar el derecho $^{31}$. El derecho faculta para oponerse al requerimiento abusivo de documentación, oposición que no puede ejercerse cuando éste no existe ya que, fuera de los límites del derecho de libertad, el administrado ha de prestar obediencia a las órdenes de la Administración en virtud de la relación de sujeción que le liga con ésta. En el caso de que el requerimiento persista y se produzca la violación del derecho se deberá acudir a los Tribunales, pero esto ya no forma parte del derecho de libertad sino que consiste en el ejercicio del derecho a la protección jurídica del Estado.

\section{Los sujetos del derecho}

\section{A) El ciudadano}

El artículo 35 de la LRJAP instituye como sujeto activo los derechos en él reconocidos al ciudadano y no ofrece precisiones respecto al titular de

\footnotetext{
${ }^{28}$ G. JellineK: Sistema dei diritti pubblici subbiettivi, op. cit., p. 47.

29 S. Romano: «Il diritto pubblico subbiettivo», op. cit., p.166 y ss., considera que por ese motivo las enumeraciones y clasificaciones de derecho de libertad no pueden tener un valor más que meramente enunciativo.
}

${ }^{30}$ Idem, pp. 163 y ss.

${ }^{31}$ Idem, pp. 169 y ss. 
los distintos derechos en él contenidos. Por tanto, una primera interpretación nos llevaría a considerar al ciudadano como titular del derecho a no presentar documentos inexigibles o reiterativos. Sin embargo, el empleo del término ciudadano ha generado polémica ya desde el momento de la tramitación parlamentaria de la LRJAP, no faltando voces que lo consideraban inadecuado ${ }^{32}$.

El problema reside en el silencio de la Constitución que no nos ofrece un concepto de ciudadano sino que parte de la presuposición del conocimiento de su contenido, aunque parece mostrar preferencia por la utilización del término ciudadano para referirse a los derechos cuyo ejercicio entraña la realización de funciones de relevancia publica ${ }^{33}$. A nuestro juicio, a pesar de las imprecisiones apuntadas, la Constitución acoge el concepto histórico de ciudadano en el artículo 13.2 que establece que solamente los españoles serán titulares de los derechos reconocidos en el artículo $23 \ldots{ }^{34}$. En dicho artículo se plasman, pues, las tres notas que tipifican el concepto de ciudadano: personalidad individual, nacionalidad y participación en la función política de gobierno ${ }^{35}$. Por tanto, sólo la persona física, de nacionalidad española y que disfrute de la plena posesión de estos derechos de acuerdo con lo establecido en las leyes responde al concepto técnico de ciudadano.

De lo expuesto se deriva la conclusión de que la utilización de dicho término no es demasiado afortunada ya que excluye del ámbito de aplicación de los mismos a los extranjeros, a las personas jurídicas y a los que por las diversas razones que la ley contempla se hallen privados del ejercicio de tales derechos, fundamentalmente el menor, el incapaz cuya incapacidad afecte al ejercicio de los mismos y el condenado a la privación de dichos derechos durante el tiempo de su condena. Como puede observarse, todos estos colectivos, a pesar de no ser ciudadanos, son susceptibles de entrar en

\footnotetext{
32 Enmienda núm. 80: En los términos establecidos en el artículo 13 de la Constitución y en sus relaciones con las Administraciones públicas, los extranjeros tendrán los mismos derechos señalados en el párrafo anterior (DOCG Congreso de los Diputados, de 7 de mayo de 1992, serie A. núm. 82-6) Fue planteada por el Grupo Parlamentario de Izquierda Unida que entendía que el término ciudadano podía crear confusión respecto de los extranjeros.

33 A. Embid Irujo: El ciudadano y la Administración, op. cit., pp. 26 y ss.

34 Tales derechos son los de sufragio activo y pasivo y el derecho de acceso a las funciones y cargos públicos, integrantes inequívocos de la función política. F. MonTIEL: «El ciudadano y el administrado», Revista de Administración Pública, núm. 48, septiembre-diciembre, 1965, pp. 127 y ss., entiende que, aunque los límites entre Gobierno y Administración no siempre son precisos, esos derechos pueden considerarse el minimum de la función política.
}

35 J. XIFra Heras: Voz «Ciudadano», en la obra colectiva Nueva Enciclopedia Jurídica, vol. IV, Seix, Barcelona, 1981, p. 164. 
relación con la Administración y ninguna razón autoriza a pensar que la LRJAP, cuyo propósito declarado es el desarrollo del carácter vicarial de la misma, pretendiese excluir a estos sujetos del ámbito de aplicación de dicho derecho. Tanto las personas jurídicas como los privados del ejercicio de sus derechos civiles podrían ser incluidos en el concepto de ciudadano mediante una interpretación extensiva que equiparase ciudadanía con nacionalidad, pero ello no evitaría que tanto los extranjeros como las personas jurídicas quedasen excluidos del ámbito de aplicación del derecho ${ }^{36}$. $\mathrm{Si}$ bien es cierto que los conceptos jurídicos evolucionan, y el de ciudadano no ha sido una excepción ${ }^{37}$, confesamos nuestro desconocimiento de esta última evolución hacia el concepto «ciudadanos del mundo» ${ }^{38}$, aunque más que de evolución podría hablarse de desaparición del mismo al privársele de una de sus notas características: la nacionalidad ${ }^{39}$. En conclusión, mediante una interpretación extensiva del término ciudadano y una investigación en la voluntad del legislador, podemos afirmar que con el término ciudadano la LRJAP designa a cualquier persona física o jurídica que se encuentre en relación con la Administración pública, lo que se corresponde con la noción de administrado que venía siendo utilizada tradicionalmente en la regulación del procedimiento administrativo ${ }^{40}$.

Procede pues, preguntarse cuál es la razón del abandono de un concepto conocido y delimitado por la doctrina para la adopción de otro que no responde eficazmente a las exigencias de precisión normativa como expre-

\footnotetext{
36 Prueba de ello es la Disposición Adicional Primera del Real Decreto 155/1996, de 2 de febrero, por el que se aprueba el Reglamento de ejecución de la Ley Orgánica 7/1985, de 1 de julio, sobre Derechos y Libertades de los Extranjeros en España, que establece expresamente la titularidad por parte de los extranjeros de los derechos del artículo 35 de La LRJAP, manifestación evidente de que el legislador es consciente de las consecuencias que pueden derivarse de la acepción convencional del término ciudadano.
}

37 Junto al concepto estricto tradicional, ha aparecido por obra del Derecho comunitario el concepto más amplio de «ciudadanía de la Unión» (artículo 8. 1, segundo inciso del TUE: Será ciudadano de la Unión toda persona que ostente la nacionalidad de un Estado miembro). Este nuevo concepto incluye derechos como el de circular y residir libremente en el territorio de la Unión y el de ser elector y elegible en las elecciones municipales en el país de residencia con independencia de la nacionalidad, vid. A. EmBiD Iruso: El ciudadano y la Administración, op. cit., pp. 24 y ss.

${ }^{38}$ Cfr. idem, p. 37.

39 Incluso en el concepto de ciudadano europeo, la nacionalidad es un dato determinante, restringido a los nacionales de los Estados miembros de la Unión como consecuencia del proceso de integración en los campos económico y político que la misma implica.

40 El Grupo Parlamentario Catalán abogó por la sustitución del término ciudadano por administrado en virtud de la mayor amplitud del mismo para referirse a todos los posibles titulares de los derechos (Enmienda núm. 268, DOCG Congreso de los Diputados, de 7 de mayo de 1992, serie A. núm. 82-6). 
sión del principio de seguridad jurídica ${ }^{41}$. El motivo parece esencialmente ideológico, al entenderse al administrado inmerso en una situación de subordinación respecto de la Administración que se pretende eliminar ${ }^{42}$. $\mathrm{Si}$ bien es posible reconducir el concepto de ciudadano mediante una interpretación histórica y de la voluntad del legislador, ello atenta contra la seguridad jurídica en tanto produce confusión respecto del ámbito de aplicación de la norma. La LRJAP es una norma llamada a ocupar una posición central en el ordenamiento administrativo y por tanto, susceptible de ser aplicada por una multiplicidad de operadores jurídicos a los que no se debe gravar con la onerosa carga de una interpretación compleja cuando se cuenta con un concepto preciso que todos ellos conocen y manejan con un alto grado de coincidencia en cuanto a su significado.

Por lo que respecta al administrado, la doctrina nos ofrece numerosas definiciones de dicho concepto, la mayor parte de las cuales se encuentran enmarcadas en la doctrina del servicio público, contemplando al administrado como usuario o destinatario del mismo ${ }^{43}$. Sin embargo, el concepto de administrado que más conviene al presente estudio por tratarse del titular de un derecho es la acepción vulgar y más amplia del mismo, que coincide con la legal y formal: el sujeto que mantiene con una persona jurídico-pública relaciones de naturaleza administrativa ${ }^{44}$. Dicha noción permite, sin interpretaciones forzadas, entender como sujetos activos del derecho tanto a los incluidos como a los excluidos del término ciudadano.

Sin embargo, el término administrado, al descansar en la idea de una relación jurídica entre la Administración y el particular y diferenciar entre administrados simples y cualificados en función de la naturaleza de tal relación, parece ligar la titularidad del derecho a la siempre polémica distinción entre relaciones de sujeción general y especial. El problema respecto del derecho que nos ocupa viene dado por la conjunción de dos factores. Por un lado, el gran poder expansivo del concepto de relaciones de sujeción especial del que la jurisprudencia ha realizado un uso entusiasta a modo de comodín para evitar las consecuencias gravosas que, para el

\footnotetext{
41 J. PRIETo DE Pedro: «Lenguaje jurídico y Estado de Derecho», RAP, núm. 140, mayo-agosto, 1996, pp. 116 y ss.

${ }^{42}$ DSCD de 16 de junio de 1992, núm. 483, pp. 14250.

${ }^{43}$ M. Cuevas: «La teoría jurídica del administrado (Apuntes para su estudio)», Revista de Derecho Público (RDP), vol. I, núm. 3, 1932, p. 75, F. MonTIEL: «El ciudadano y el administrado», op. cit., p. 128 y A. De JuAN ABAD: «Sobre el concepto de administrado», Documentación Administrativa (DA), núm. 56-57, agosto-septiembre, 1962, p. 68.
}

44 E. Serrano Guirado: Voz «Administrado», en la obra colectiva Nueva Enciclopedia Jurídica, vol. II, Seix, Barcelona, 1983 (reimpresión), p. 378. 
interés general, se derivarían de la aplicación estricta bien del principio de legalidad, bien de los derechos fundamentales ${ }^{45}$. Por otro, la consideración de este derecho como uno de los llamados a integrar el «estatuto ordinario del administrado» ${ }^{46}$ parece asimilar dicho concepto al de administrado simple ${ }^{47}$. Por tanto, la conjunción de ambos factores podría suponer un recorte en la aplicación de este derecho, a pesar de que entendemos que la relación a tener en cuenta en este caso sería la procesal, que difícilmente podría ser considerada una relación de sujeción especial ${ }^{48}$.

Tanto la problemática del término ciudadano como la que pudiera derivarse de un incorrecto entendimiento del concepto de administrado podrían haberse evitado con el empleo de la noción de interesado, mucho más congruente con la naturaleza procedimiental del derecho que nos ocupa $^{49}$.

\section{B) La Administración}

A diferencia de la imprecisión observada en lo que al sujeto activo del derecho se refiere, el artículo 35. f) se ocupa de concretar quién ostenta la condición de sujeto pasivo del derecho: la Administración actuante. Ello, no obstante, no resulta tan esclarecedor como en un primer momento pudiera parecer al tratase de un término inusual en la legislación en materia de procedimiento administrativo ${ }^{50}$. Por tanto, es necesario precisar

45 I. Lasagabaster Herrarte: Las relaciones de sujeción especial, Civitas, Madrid, 1994, pp. 170 y ss. Hay que tener en cuenta que la jurisprudencia, aparte de aquellas relaciones consideradas tradicionalmente de sujeción especial, ha ampliado el concepto a situaciones tales como la titularidad de licencias de auto-taxi, los espectadores de corridas de toros... vid. R. García MACHO: Las relaciones de especial sujeción en la Constitución española, Tecnos, Madrid, 1992, pp. 212 y ss.

46 E. García de EnTERRIA: «Algunas reflexiones sobre el Proyecto de Ley de Régimen Jurídico de las Administraciones Públicas y del Procedimiento Administrativo Común», op. cit., p. 328.

47 J. GonZáLEZ Pérez El administrado, Abella, Madrid, 1966, p. 20. El administrado simple sería «el auténtico administrado, esto es, el administrado que no se encuentra en alguna de las situaciones cualificadas».

48 E. Serrano Guirado: Voz «Administrado», op. cit., pp. 380 y ss., estima que la configuración del procedimiento administrativo como conjunto de instituciones procesales que sirven de soporte a la actividad de la Administración, crea una situación objetiva y general que es característica de las relaciones de sujeción general.

49 J. GonZÁlez Pérez: Voz «Interesado», en la obra colectiva Nueva Enciclopedia Jurídica, vol. XIII, Seix, Barcelona, 1968, pp. 227, considera al interesado como «el administrado en cuanto interviene o puede intervenir en el procedimiento administrativo»

50 J.A. Santamaría Pastor: Comentario sistemático a la Ley de Régimen Jurídico de las Admi- 
cuál es su significado, ya que de la delimitación del mismo depende la extensión del ámbito de aplicación del derecho. Para proceder a dicha delimitación consideramos imprescindible analizar por separado los dos conceptos que conforman el término Administración actuante. De este modo, intentaremos determinar cuándo nos hallamos en presencia de una Administración pública para después determinar qué se entiende por Administración actuante a los efectos de la exigibilidad del derecho cuyo estudio nos ocupa.

La propia LRJAP, en su artículo 2, nos ofrece una relación de los entes que ostentan la condición de Administraciones públicas a los efectos de la aplicación de la misma y, por tanto, sujetos pasivos de este derecho. Por una parte, están las tradicionalmente denominadas Administraciones territoriales, que no presentan mayores dificultades ${ }^{51}$. Son las titulares de los poderes públicos superiores y de ellas dependen el resto de Administraciones públicas ${ }^{52}$. Por otra, las Entidades de Derecho Público con personalidad jurídica propia vinculadas o dependientes de cualquiera de las Administraciones públicas, es decir, la denominada Administración institucional, caracterizada tanto por su instrumentalidad como por su creación por una Administración pública ${ }^{53}$.

La Administración institucional comenzó su andadura como técnica organizativa que persigue, mediante la personificación y manteniendo un control que la convierte en ente instrumental, compensar el aumento de las funciones asumidas por la Administración. Sin embargo ha derivado en el fenómeno denominado «huida del Derecho administrativo» ${ }^{54}$, que no ha podido ser atajado ni siquiera por la LOFAGE, cuyo propósito declarado es racionalizar la normativa de la Administración institucional, ya que la entusiasta acogida de la anterior normativa estatal por las Comunidades

nistraciones Públicas y el Procedimiento Administrativo Común, Libros Jurídicos Carperi, Madrid, 1993, p. 49, lo considera importado de la terminología propia del Derecho urbanístico.

51 Es conveniente dejar constancia, en el ámbito de la Administración local, del problema de los Consorcios cuya configuración como entes locales ha planteado variados interrogantes a los que viene a dar respuesta la STS de 30 de abril de 1999 (Ar. 4692), que expresa la necesidad de analizar cada supuesto concreto, habida cuenta de la pluralidad de realidades jurídicas cobijadas bajo la denominación genérica de consorcio, señalando las características que ha de reunir dicha figura a los efectos de su calificación como entidad local.

52 E. García de Enterría y T.R. Fernández Rodríguez: Curso de Derecho Administrativo, vol. I, Civitas, Madrid, 2000, pp. 378 y ss.

53 Artículo 41 de la LOFAGE.

54 M.F. Clavero Arévalo: «Personalidad jurídica, derecho general y derecho singular de las Administraciones autónomas», DA, núm. 58, octubre, 1962, p. 16. 
Autónomas ha permitido el profuso desarrollo de la técnica del ejercicio de funciones públicas a través de formulas societarias ${ }^{55}$. Esta situación es difícil de remediar por vía legislativa ya que las Comunidades Autónomas gozan de competencia exclusiva para la organización de sus propias instituciones ${ }^{56}$, lo que conlleva una diferenciación de tratamiento de los particulares ante las distintas Administraciones, habida cuenta del giro experimentado por la normativa estatal.

El problema consiste en que dichas sociedades que generalmente adoptan la forma de sociedad anónima, por imperativo de la LSA tienen naturaleza mercantil y se someten a las normas de Derecho privado ${ }^{57}$. Sin perjuicio de que determinados aspectos de su actividad puedan remitirse en su regulación a normas de Derecho administrativo, sus acuerdos y decisiones se adoptan conforme a las normas de Derecho privado eludiendo la aplicación de la LRJAP, lo que incide directamente en este derecho que ostentan los interesados en el procedimiento administrativo.

Un fenómeno similar se produce en el ámbito local, en el que nos encontramos con las sociedades de capital íntegramente público como opción organizativa para la prestación directa de los servicios municipales. Estas sociedades que, a diferencia de las del Estado y Comunidades Autónomas, pueden constituirse en forma anónima o limitada, tampoco pueden considerarse Administraciones públicas a los efectos de la exigibilidad del derecho por razones idénticas a las expuestas para las sociedades de capital público autonómico.

Por tanto, nos encontramos con que una simple decisión organizativa conlleva un cambio en el «estatuto ordinario del administrado», con la circunstancia agravante de que la decisión de la adopción de una fórmula societaria se materializa mediante ley, por lo que un mecanismo que, en principio, supone una garantía para los administrados acaba por convertirse en un obstáculo para su defensa, dadas la inatacabilidad de la misma

\footnotetext{
55 S. Del Saz: «Desarrollo y crisis del Derecho Administrativo. Su reserva constitucional», en la obra colectiva Nuevas Perspectivas del Derecho Administrativo. Tres estudios, Civitas, Madrid, 1992, pp. 146 y ss.

56 A modo de ejemplo de esta tendencia valga el artículo 49.2 del Estatuto de Autonomía del Principado de Asturias que establece que el Principado podrá constituir empresas públicas como medio de ejecución de las funciones que sean de su competencia, según lo establecido en el presente Estatuto.

57 Artículo 3 de la LSA: La Sociedad Anónima, cualquiera que sea su objeto, tendrá carácter mercantil, y en cuanto no se rija por disposición que le sea específicamente aplicable, quedará sometida a los preceptos de esta ley.
} 
ante los Tribunales ordinarios y la carencia de legitimación de éstos en un eventual recurso de inconstitucionalidad.

Sea cual fuere la solución para atajar este uso abusivo de las personificaciones de Derecho privado, resulta evidente que las mismas no pueden ser consideradas como Administraciones públicas respecto de la aplicabilidad del derecho que nos ocupa por su naturaleza de Derecho procedimental. La única fórmula posible para evitar la diferenciación de los medios de defensa de los particulares que conlleva esta situación consistiría en un comportamiento consecuente del legislador que le llevase a someter a dichas sociedades al procedimiento administrativo cuando ejerzan potestades administrativas, en virtud de sus competencias básicas sobre procedimiento administrativo común. Dado que el motivo de la sumisión de las entidades de Derecho público a la LRJAP es la conciencia, por parte del legislador, de que el ejercicio de potestades administrativas debe estar sometido a las normas de procedimiento administrativo en virtud de su doble dimensión de garantía del interés público y garantía de los derechos de los administrados ${ }^{58}$, una postura coherente requeriría idéntico tratamiento para las sociedades de capital público cuando ejerciten dichas potestades, a lo que estimamos no puede oponerse su sumisión al Derecho privado, especialmente si tenemos en cuenta que el mismo sufre excepciones por disposición expresa del legislador en otras materias ${ }^{59}$.

Una vez precisado lo que podemos entender por Administraciones públicas a los efectos del derecho a no presentar documentos inexigibles o reiterativos, pasaremos a examinar el concepto de Administración actuante. El Diccionario de la Real Academia define actuante, participio activo del verbo actuar, como «el que actúa» y por actuar, en su acepción propia en Derecho, entiende «formar autos, proceder judicialmente». Es decir, la acepción específica pertenece al Derecho procesal por lo que sería plenamente aplicable al procedimiento según la concepción amplia del proceso como instrumento para el ejercicio de una función pública ${ }^{60}$. En conclusión, sería Administración actuante la que, en cada momento de la tramitación del procedimiento administrativo, tiene encomendada la competencia para realizar las actuaciones que lo conforman.

\footnotetext{
58 R. Entrena Cuesta: Curso de Derecho Administrativo, Tecnos, Madrid, 1994, p. 224.

59 A modo de ejemplo, valga la Disposición Adicional Sexta de la LCAP que somete a las sociedades de capital mayoritariamente público a los principios de publicidad y concurrencia.

60 M. Ballbé PrunÉ: «La esencia del proceso (El proceso y la función administrativa)», Revista General de Legislación y Jurisprudencia (RGLJ), núm. 182, julio-agosto, 1947, pp. 39 y ss.
} 
Estimamos que tal consideración se referiría las Administraciones territoriales y los organismos públicos dependientes de cada una de ellas, sin que el dato de la personalidad jurídica independiente de los mismos afecte a la exigibilidad del derecho. En primer lugar, porque tal parece la voluntad del legislador que excluyó expresamente en su momento la posibilidad de que el ámbito de aplicación del derecho se refiriese a todas las Administraciones públicas ${ }^{61}$. En segundo lugar, tanto la doctrina como la jurisprudencia manifiestan su acuerdo sobre el hecho de que el dato de la personalidad jurídica no es en sí mismo identificador de un concreto régimen jurídico, ya que se predica tanto de las distintas Administraciones territoriales como de la multitud de entes con diverso régimen jurídico de la personalidad ${ }^{62}$. En la misma línea se orienta la jurisprudencia que considera que, aunque tienen personalidad jurídica y patrimonio propio, no son personas independientes y que refiere el ámbito de la personalidad jurídica única consagrada por la LRJAP a cada una de las distintas Administraciones territoriales ${ }^{63}$. Por último, en tal sentido parece asimismo inclinarse la escasa jurisprudencia menor existente sobre el derecho a no presentar documentos inexigibles o reiterativos ${ }^{64}$.

\section{EL CONTENIDO DEL DERECHO: LA FACULTAD DE NO PRESENTACIÓN}

El artículo 35. f) de la LRJAP determina como contenido del derecho la facultad de no presentar documentos inexigibles o reiterativos al procedimiento. Por ello, procede, en primer lugar, determinar el alcance de la facultad de no presentar para después precisar el concepto de documentos inexigibles y reiterativos, de manera que podamos determinar el contenido del derecho.

\footnotetext{
${ }^{61}$ El Grupo Parlamentario Popular presentó en su momento una enmienda en la que se proponía modificar la expresión «Administración actuante» por «en poder de cualquiera de las Administraciones públicas» (Enmienda núm. 448, DOGC Congreso de los Diputados de 7 de mayo de 1992. serie A. núm. 82-6). Fue rechazada precisando que la expresión Administración actuante no se refería a Administraciones diferentes a la que tramitase en procedimiento en cada caso concreto (DSCD de 16 de junio de 1992, núm. 483, p. 14251).

62 Por todos, G. ArIÑo OrTiz: La Administración institucional (Bases de su régimen jurídico), IEA, Madrid, 1972, pp. 48 y ss. y STS de 22 de junio de 1986 (Ar. 5549).

63 STS de 18 de febrero de 1998 (Ar. 1679), STS 31 de marzo de 1981 (Ar. 981) y STS de 26 de noviembre de 1994 (Ar. 8953).

${ }^{64}$ STSJ (Baleares) de 7 de noviembre de 1995 (Ar. 814) y STSJ (Baleares) de 24 de septiembre de 1996 (Ar. 1233).
} 
Es oportuno hacer notar la dificultad de precisar el contenido de un derecho cuya parca redacción legal causa unas deficiencias técnicas que se hicieron notar ya en sede parlamentaria mediante la presentación de una enmienda que mejoraba sustancialmente la redacción del mismo en dos sentidos ${ }^{65}$. Por un lado, mostraba claramente su naturaleza procedimental, al ligar su existencia al desenvolvimiento de un procedimiento, precisando su exigibilidad en cualquier fase procesal. Por otro, revelaba con claridad su finalidad instrumental: coadyuvar a que los derechos o intereses que se sustancian en el procedimiento no sufran dilación o merma alguna por causa de una petición abusiva de documentación por parte de la Administración. Desafortunadamente, dicha enmienda no mereció siquiera una alusión en el debate parlamentario, pasando al texto definitivo de la LRJAP la redacción que figuraba en el Proyecto de Ley. Sin embargo, estimamos que el silencio favorece una utilización de lo anteriormente expuesto al objeto de determinar el contenido de la facultad de no presentación en que el derecho se concreta, ya que si el legislador no manifestó un rechazo expreso a la enmienda, puede inferirse que consideró innecesaria la precisión técnica al entender que tal contenido se encontraba comprendido redacción por él mismo propuesta ${ }^{66}$.

El Diccionario de la Real Academia define presentación como «acción y efecto de presentar» y presentar como «hacer manifestación de una cosa, ponerla en presencia de alguien», «comparecer en algún lugar» y «comparecer ante un jefe o autoridad de quien se depende». Por tanto, el acto de presentación define los tres elementos que conlleva la satisfacción de una petición documental administrativa: existencia de una petición realizada por la autoridad $\mathrm{u}$ órgano administrativo competente para la tramitación del procedimiento, comparecencia personal del administrado ante el mismo y la puesta en su presencia del documento requerido. Por añadidura, dicho término lleva implícito la nota de la dependencia, que siempre se encuentra presente en este tipo de peticiones cuya desatención por parte del administrado derivaría en la suspensión y eventual caducidad del procedimiento.

Por tanto, entendemos que la facultad de no presentación consiste en el poder concedido al administrado de negarse a exhibir ante la autoridad $\mathrm{u}$

\footnotetext{
65 Enmienda núm. 223: A que la incoación, tramitación y resolución del procedimiento no quede condicionada a la presentación de documentos distintos de los expresamente exigidos por las normas aplicables al procedimiento de que se trate o a la aportación de los que ya se encuentren en poder de la Administración actuante (DOCG Congreso de los Diputados, de 7 de mayo de 1992, serie A. núm. 82-6)

${ }^{66}$ Estimamos que en apoyo de este razonamiento abunda la encendida polémica suscitada por las enmiendas que perseguían la sustitución del término ciudadano por el de administrado.
} 
órgano administrativo requirente aquellos documentos que le sean solicitados por éste y que no sean exigibles o resulten reiterativos, sin que ello impida la incoación del procedimiento o suponga la suspensión y/o caducidad de la tramitación o resolución del mismo.

En cuanto a los conceptos de documentos inexigibles o reiterativos, hay que señalar que, pese a ser el procedimiento administrativo esencialmente escrito y por tanto de naturaleza documental, su normativa no ofrece un tratamiento sistemático del tema, limitándose a regular aspectos puntuales del mismo, abandonando el resto a los usos que pueda desarrollar la Administración ${ }^{67}$. Ante esta situación entendemos que el reconocimiento del derecho que nos ocupa produce dos consecuencias significativas. En primer lugar, la inclusión del concepto de documento en la legislación de procedimiento administrativo, hecho infrecuente ya que las referencias de la misma a la materia documental aparecen ligadas al término expediente ${ }^{68}$. En segundo lugar, el empleo del mismo desde la perspectiva del administrado lo que conlleva la utilización de una acepción amplia, comprensiva de todo tipo de documentos.

Por lo que se refiere a la primera de las cuestiones comentadas, la definición de expediente se recoge en el Real Decreto 2568/1986, de 28 de noviembre, por el que se aprueba el Reglamento de Organización, Funcionamiento y Régimen Jurídico de las Entidades Locales, del que podemos deducir una primera aproximación a la idea del documento como una parte individualizable del expediente ${ }^{69}$. Esto, unido a la perspectiva del derecho como derecho del administrado, obliga a considerar la acepción amplia del término documento. Tradicionalmente, se venía identificando documento con escrito por ser hasta fecha reciente la escritura el único signo o grafismo que podía dar cuenta de los hechos con trascendencia jurídica ${ }^{70}$. La aparición de medios técnicos capaces de acreditar tales hechos mediante signos distintos de la escritura manual o mecánica, motiva la aparición de

\footnotetext{
67 Artículo 46 de la LRJAP que regula la validez y eficacia de las copias de los documentos.

${ }^{68}$ La única referencia a documentos con sustantividad propia en la LRJAP es la relativa a las actas de sesiones de los órganos colegiados recogida en el artículo 27. Hay que hacer constar que sus aps. 2, 3 y 5 no tiene carácter básico según la STC 50/1999, de 6 de abril, F. J. 8.
}

69 Artículo 164: 1. Constituye el expediente el conjunto ordenado de documentos y actuaciones que sirven de antecedentes y fundamentos de la resolución administrativa, así como de las diligencias encaminadas a ejecutarla.

2. Los expedientes se formaran mediante la agregación sucesiva de cuantos documentos, pruebas, dictámenes, Decretos, acuerdos, notificaciones y demás diligencias deban integrarlo...

70 J. Morán del CASERo: «Documentos y expedientes administrativos (I)», DA, núm. 122, marzoabril, 1968, p. 93. 
un concepto amplio que no sólo considera como tales los escritos sino también «toda cosa mueble que pueda ser llevada a presencia del órgano decisor» ${ }^{71}$. Sin embargo, en lo que al procedimiento administrativo se refiere, parece más adecuada la noción de documento que pone el acento en el hecho de la posibilidad de incorporación directa de la cosa mueble al expediente ya que las que no son susceptibles de dicha operación se reducen a un escrito mediante acta de reconocimiento o inspección ${ }^{72}$. Por tanto, podríamos definir como documentos «aquellas cosas que directamente revelan o acreditan hechos jurídicos, y que, por su índole, pueden ser directamente incorporadas a un expediente» ${ }^{73}$. Es decir, habría que considerar como tales, no sólo los tradicionales documentos públicos y privados sino también de realidades tales como fotografías, planos, etc.

Mención aparte merece el fenómeno de los documentos electrónicos, entendidos como aquellos generados, trasmitidos o transcritos por medios electrónicos. El problema que los mismos plantean es su soporte, que no es el papel como en el resto de documentos analizados y su lenguaje, que no está constituido por palabras, grafismos o imágenes ${ }^{74}$. Aunque en la mayoría de los casos no presentan dificultades ya que los medios electrónicos suponen un simple soporte de la información que puede ser reducida a papel y adoptar por tanto la forma de un documento tradicional, existen ciertos casos problemáticos. El primero consiste en el documento creado por datos almacenados en la memoria de un ordenador. El segundo, aquel que ha sido sometido a un tratamiento de comunicaciones por medios telemáticos. Ambos presentan el problema de su originalidad y validez ya que, para ser exteriorizados al lenguaje natural, han de ser sometidos a un procesamiento que conlleva la posibilidad de modificación de su contenido ${ }^{75}$. Dado que la regulación sobre validez y eficacia de los documentos contenida en la LRAP remite a cada uno de ellos a su normativa reguladora específica, nos encontramos con que el problema principal se centra en el documento electrónico administrativo, ya que otras ramas del Ordenamiento han procedido a la admisión del mismo determinando las garantías en orden a asegurar su validez y originalidad ${ }^{76}$. Aunque la

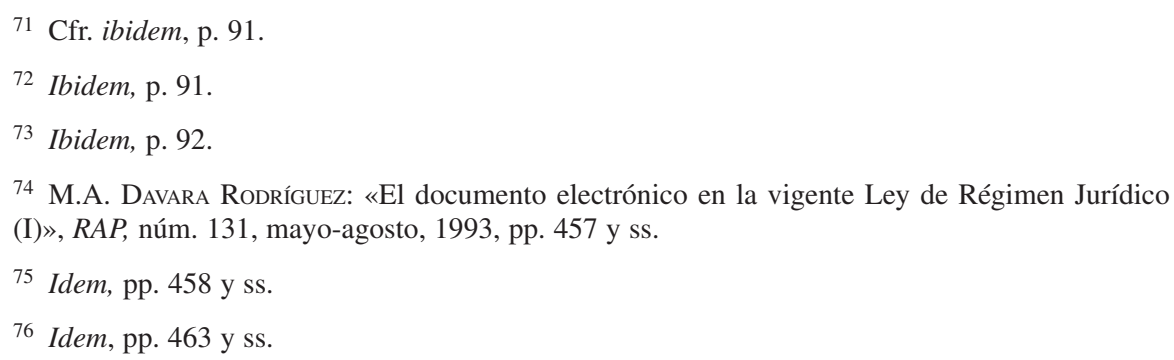


LRJAP parece ser partidaria de reconocer la validez de dichos documentos, entendemos que su regulación es demasiado ambigua, limitándose a enunciar principios generales sin aportar mecanismo alguno de garantía de los mismos dado que los remite al régimen general de validez y eficacia del acto ${ }^{77}$, lo que resulta inadecuado en virtud de los particulares problemas que plantean estos documentos ${ }^{78}$.

Una vez determinado el alcance del concepto de documento corresponde examinar lo que se entiende por documento inexigible o reiterativo en orden a determinar la extensión y límites de la facultad de no presentación.

Por documentos inexigibles entiende el artículo 35. f) de la LRJAP aquellos no exigidos por las normas aplicables al procedimiento de que se trate. Con ello se trata de imponer la exigencia de predeterminación normativa de las aportaciones documentales, lo que, conectado con la regulación mediante motivos tasados de la subsanación y mejora de la solicitud y la necesidad de justificación de las peticiones de informes no preceptivos, vendría a intentar atajar las solicitudes arbitrarias de documentos. Esta necesidad de regulación presentaría dos aspectos: formal y material.

Por lo que respecta al primero, lo humilde de esta clase de regulaciones nos lleva al terreno de las Circulares e Instrucciones que serán, las más de las veces, las que determinen los documentos exigibles. Estas disposiciones se definen como el medio a través del que se ejerce la potestad jerárquica de los órganos superiores de la Administración sobre los órganos subordinados ${ }^{79}$. De esto se deduce que carecen de valor normativo no obstante lo cual el propio precepto prevé su publicación en el Diario Oficial que corresponda cuando se estime conveniente en razón de los destinatarios o de los efectos que pueda producir. Dicha previsión no resulta dema-

\footnotetext{
77 Artículo 45.5 de la LRJAP: Los documentos emitidos, cualquiera que sea su soporte, por medios electrónicos, informáticos o telemáticos por las Administraciones públicas, o lo que éstas emitan como copias de originales almacenados por estos mismos medios, gozarán de la validez y eficacia de documento original, siempre que quede garantizada su autenticidad, integridad y conservación y, en su caso, la recepción por el interesado, así como el cumplimiento de las garantías y requisitos exigidos por éstas u otras Leyes.

78 Existen disposiciones sectoriales que regulan dichos aspectos tales como el artículo 91 del Real Decreto 1098/2001, de 12 de octubre, por el que se aprueba el Reglamento General de la Ley de Contratos de las Administraciones Públicas, que establece que la solicitud de participación en un procedimiento restringido efectuada por correo electrónico sólo será válida y podrá ser reducida a copia impresa e incorporadas al expediente, cuando exista constancia de la transmisión y recepción, de sus fechas y del contenido integro de las comunicaciones y se identifique fidedignamente al remitente y al destinatario.
}

79 Artículo 21 de la LRJAP. 
siado coherente con su definición como órdenes jerárquicas, de acuerdo con la cual no deberían tener más destinatario que el órgano subordinado y sus efectos se producirían exclusivamente ad intra de la organización administrativa. De esta ambigua redacción se deduce que continuarán utilizándose para cobijar verdaderas normas jurídicas que vinculan a los administrados.

En el caso que nos ocupa, los problemas que plantean son esenciales por cuanto delimitan el objeto de un derecho reconocido por la ley. No ayuda al esclarecimiento de la cuestión la divergencia entre la jurisprudencia del Tribunal Constitucional y la del Tribunal Supremo, que además no sigue una línea clara en la materia ${ }^{80}$. La doctrina no parece ponerse tampoco de acuerdo ya que junto a la línea mayoritaria que rechaza la naturaleza normativa de estas disposiciones por la falta de competencia de las autoridades menores para dictar reglamentos, no faltan voces que defienden su utilización cuando exista una habilitación tácita o expresa contenida en una norma con rango de ley ${ }^{81}$. El Tribunal Constitucional, de acuerdo con la doctrina mayoritaria a cuya opinión nos adherimos, niega su naturaleza normativa pero, consciente del uso que de las mismas realiza la Administración, reconoce que pueden vulnerar derechos fundamentales y, por tanto, considera legitimado al administrado para recurrir en vía contencioso-administrativa y de amparo aun cuando no se hayan producido los actos de aplicación ${ }^{82}$, lo que supone una asimilación a las disposiciones generales en lo que al régimen de impugnación se refiere. Por su parte, el Tribunal Supremo tanto niega como afirma su naturaleza normativa, incluyendo entre los supuestos de Circulares con valor normativo las que se refieren a exigencias documentales siempre que cumplan con el requisito de publicación al entender que ello condiciona la eficacia ad extra de las normas jurídicas, por lo que parece probable que la situación se mantenga dada la imposición legal del mismo por la LRJAP ${ }^{83}$.

En cuanto al aspecto material de la regulación de los documentos inexigibles es necesario señalar que, a nuestro juicio, no puede procederse a una regulación rígida de los contenidos documentales de cada tipo de procedimiento ya que ello supondría la proscripción de todo tipo de solicitud com-

\footnotetext{
${ }^{80}$ M. A. DaVARA RodríGuEZ: «El documento electrónico en la vigente Ley de Régimen Jurídico (I)», op. cit., in totum.

81 Por todos, E. García de EnTerría y T. R. Fernández Rodríguez: Curso de Derecho Administrativo, vol. I, op. cit., pp. 189 y ss.

82 Por todas, STC 26/1986, de 19 de febrero, F. J. 1 y 2 y STC 150/1994, de 23 de mayo, F. J. 5.

${ }^{83}$ STS 18 de marzo de 1996 (Ar. 2529).
} 
plementaria de documentación, consecuencia desaconsejable por motivos tanto teóricos como prácticos. Por lo que respecta a los primeros, dicha proscripción en modo alguno es el propósito de un derecho encaminado únicamente a otorgar al administrado un medio de defensa frente a comportamientos de carácter abusivo. En cuanto a los segundos, desde un punto de vista práctico, resulta imposible ya que la inherente variedad de circunstancias concurrentes en cada caso singular impiden una previsión normativa de todas las necesidades documentales posibles en cada tipo de procedimiento. Estas circunstancias hacen imprescindible la subsistencia de un margen de discrecionalidad que permita a la Administración realizar dichas solicitudes cuando sean necesarias para el normal desarrollo del procedimiento. Por tanto, la predeterminación normativa que el derecho impone no sólo no excluye esta posibilidad, sino que constituye una pauta interpretativa que suministra criterios de razonabilidad y proporcionalidad en orden a la valoración de la necesidad de las solicitudes complementarias de documentación dentro de cada tipo de procedimiento. Ahora bien, para el cumplimiento de dicha función resultaría necesario imponer legalmente la necesidad de motivación de dichas solicitudes en orden a una eventual revisión por los Tribunales, especialmente necesaria en este caso que ha sido considerado por la jurisprudencia como un supuesto de discrecionalidad técnica ${ }^{84}$.

Por lo que respecta a los documentos reiterativos, son definidos por la LRJAP como los que se encuentran en poder de la Administración actuante. Entendemos que una interpretación no restrictiva de los derechos de los administrados y coherente con el objetivo de simplificación procedimental perseguido por la norma exige entender como tales, no sólo a los documentos aportados a lo largo del procedimiento en curso sino también a los que ya obren en los archivos administrativos con motivo de otros anteriores o por haberlos producido ella misma ${ }^{85}$, línea que ha sido seguida por los legisladores autonómicos en la materia. Entendemos que este derecho debe regirse por el principio de facilidad por el cual los documentos deben ser acreditados por la parte a la que resulte menos gravoso hacerlo ${ }^{86}$.

\footnotetext{
84 T. R. Fernández Rodríguez: De la arbitrariedad de la Administración, Civitas, Madrid, 1997, pp. 61 y ss., considera afectado por la categoría de la discrecionalidad técnica las medidas relativas a la organización de los servicios públicos, dentro de las que pueden incluirse las reglamentaciones referidas a la documentación necesaria en cada tipo de procedimiento.
}

85 STSJ (La Rioja) de 7 de octubre de 1997 (Actualidad Administrativa [AA], núm. 5, mayo, 1998, marg. 241): por lo que respecta a los documentos creados por la propia Administración —hojas de servicio en el caso concreto- se entiende que es obligación de la Administración competente aportarlos y no gravar al administrado con la carga de conseguir una copia autenticada para su posterior presentación.

86 J. R. Chaves García: Los derechos de los ciudadanos ante las Administraciones públicas, Trea, Gijón, 1999, pp. 82 y ss. Aunque nacido en el ámbito del proceso judicial, en el que como princi- 
Existen, sin embargo, tres supuestos en los que el ejercicio del derecho debe ceder por diferentes causas. En primer lugar, los documentos contenidos en aquellas dependencias de la Administración pública en las que para la obtención de información se requiere la solicitud personal del administrado ${ }^{87}$. En segundo lugar, los llamados documentos administrativos de exhibición ya que su presentación se encuentra íntimamente relacionada con el ejercicio de funciones de control por parte de la Administración para las que la LRJAP establece el deber especifico de colaboración ${ }^{88}$. Por último, nos encontramos con el supuesto de pérdida o extravío del documento por parte del órgano instructor del procedimiento. En este caso, entendemos que la reiteración sería inevitable aun cuando la presentación se hubiera producido dentro del mismo procedimiento, lo que constituye uno de los puntos vulnerables de la regulación del derecho, ya que la falta de precisión de la norma se presta a favorecer un uso abusivo de esta posibilidad, especialmente en los casos en que la presentación se hubiera efectuado en procedimiento diferente de aquel del que trae causa la petición documental. Por ello, entendemos plenamente acertada la exigencia del artículo 2 del Real Decreto 1778/1994, de 5 de agosto, por el que se adecuan las normas reguladoras de los procedimientos de otorgamiento, modificación y extinción de autorizaciones, que exige que la imposibilidad material de obtención del documento conste debidamente justificada en el expediente, previsión que, a nuestro juicio, debería incluirse en las regulaciones de cualquier procedimiento en pro de una mayor garantía del derecho. En la misma línea parece inclinarse la jurisprudencia que considera imprescindible la motivación de los actos que limiten o eliminen derechos subjetivos de los administrados ${ }^{89}$.

No podemos abandonar este tema sin hacer mención de la opinión sustentada por algunos autores, que estiman que el cumplimiento por parte

pio general rige la aportación de la prueba, estimamos que resulta plenamente aplicable al procedimiento administrativo según la concepción amplia del mismo que sostenemos y la función de acreditación de hechos con relevancia jurídica que cumplen los documentos dentro del mismo.

87 A. SÁnchez Blanco: «Los derechos de los ciudadanos en la Ley de las Administraciones públicas», RAP, núm. 132, septiembre-diciembre, 1993, p. 53, cita los casos del Catastro, el Censo electoral y los Registros Civil, de la Propiedad y Mercantil.

88 J. Pérez: Comentarios a la Ley de Régimen Jurídico de las Administraciones Públicas y del Procedimiento Administrativo Común (Ley 30/1992, de 26 de noviembre), op. cit., p. 954, incluye entre los mismos los documentos de identificación personal generales y especiales, los documentos de identificación real y otros documentos como los salvoconductos, permisos de conducir y licencias varias. El deber de colaboración se regula en el artículo 39.1 en los siguientes términos: Los ciudadanos están obligados a facilitar a la Administración informes, inspecciones y otros actos de investigación sólo en los casos previstos por las Leyes.

89 STS de 29 de noviembre de 1985 (Ar. 5574). 
del documento del requisito de la exigibilidad obstaculizaría el ejercicio de la facultad de no presentación en el caso de reiteración, ya que difícilmente podría negarse el interesado a aportarlo al estar obligado por las normas reguladoras del concreto procedimiento ${ }^{90}$. No podemos compartir tal opinión ya que el derecho configura, a nuestro juicio, una facultad que recae sobre dos ámbitos materiales estrechamente relacionados pero diferentes. Por un lado, cuando la facultad de no presentar tiene por objeto los documentos inexigibles se refiere a los supuestos específicos de peticiones documentales no establecidas en las normas reguladoras del procedimiento, mientras que cuando recae sobre los documentos reiterativos opera en un ámbito general, ya que la previsión normativa en forma alguna impide que la satisfacción de la misma sea reiterativa por encontrarse ya en poder de la Administración actuante el documento concreto. Entendemos que viene en apoyo de esta interpretación la finalidad del propio derecho, concebido como el instrumento jurídico adecuado para la defensa de los ciudadanos ante las peticiones abusivas de documentación. Teniendo en cuenta que dicho fenómeno presenta una vertiente activa, consistente en las peticiones sin apoyo normativo y una vertiente pasiva, configurada como la negativa a considerar válido a los efectos del procedimiento el mismo documento presentado en el mismo o anterior procedimiento, el derecho debe abarcar ambas posibilidades ya que de lo contrario su reconocimiento legal carecería de sentido.

\section{RECAPITULACIÓN}

De todo lo visto a lo largo de este análisis podemos concluir que, pese a la instrumentalidad del derecho a no presentar documentos inexigibles o reiterativos, nos encontramos en presencia de un derecho público subjetivo en cuanto podemos detectar sus elementos esenciales: interés protegido, objeto, sujetos y contenido.

Sin embargo, podemos reseñar dos deficiencias. Por un lado, la inadecuada utilización del término ciudadano como titular del derecho que genera confusión y ha requerido reformas puntuales por parte del legislador. Por otro, la brevedad del enunciado legal del mismo, que no refleja adecuadamente su naturaleza procedimental y obliga a una labor de inter-

\footnotetext{
90 J. M. BAÑo León: «Los interesados y los derechos y deberes de los ciudadanos ante la Administración», en la obra colectiva La nueva Ley de Régimen Jurídico de las Administraciones Públicas y del Procedimiento Administrativo Común, Tecnos, Madrid, 1993, p. 89.
} 
pretación para determinar su extensión y límites inadecuada para el operador jurídico al que la LRJAP va dirigida.

Por último, es necesario hacer una breve reflexión sobre el principal problema que, a nuestro juicio, condiciona el ejercicio del derecho. Es necesaria la mejora tanto de los mecanismos de coordinación de los distintos órganos de las Administraciones públicas como de la operatividad del sistema de archivos y registros administrativos, ya que la consecución de un nivel adecuado de funcionamiento de ambos constituye el presupuesto de la efectividad del derecho que nos ocupa.

Por todo lo expuesto, consideramos imprescindible que el legislador haga uso de la iniciativa que le corresponde y acometa tanto una reforma de la regulación del derecho que subsane los defectos estructurales presentados, con lo que se evitaría la dilación de su plena operatividad que supondrá la espera a que la jurisprudencia delimite sus distintos aspectos, como la adopción de aquellas medidas tendentes a subsanar los problemas de organización y funcionamiento de la Administración, sin cuya aminoración el derecho que nos ocupa verá su ejercicio muy limitado cuando no impedido. 